\title{
Confirming Deliberate Practice in Dietetics Education
}

\author{
Kevin Haubrick (Corresponding author) \\ The University of Houston, Houston, USA \\ E-mail: khaubrick@uh.edu \\ Elaine F. Molaison \\ The University of Alabama, USA \\ Richard Mohn \\ The University of Southern Mississippi, USA \\ Holly Huye \\ The University of Southern Mississippi, USA
}

\author{
Alicia S. Landry \\ University of Central Arkansas, USA
}

Received: September 8, 2019

Accepted: October 5, 2019 Published: December 5, 2019

doi:10.5296/jet.v7i1.15985

URL: http://dx.doi.org/10.5296/jet.v7i1.15985

\begin{abstract}
Objective: To develop a valid and reliable instrument to define deliberate practice in dietetics education.

Design: Instrument development.

Setting: Dietetics education and supervision.

Participants: Twenty-three Registered Dietitians participated in the preliminary item tryout phase of the project and a total of 323 participants launched the instrument link for construct validation.
\end{abstract}

Main Outcome Measure(s): Fifty-five deliberate practice statements were tested for construct validation.

Analysis: Face and content validity of the instrument, along with initial reliability estimated were tested in the preliminary item tryout phase. Exploratory factor analysis was utilized to determine construct validity of the instrument.

Results: Initial reliability estimates were $>.70$ for most categories during the preliminary item tryout phase. Exploratory factor analysis resulted in a seven-factor solution with 32 items accounting for $59.72 \%$ of the shared variance. 
Conclusion and Implications: Deliberate practice can be defined with the following characteristics: (1) opportunities to practice skills and hone knowledge; (2) experiential practice to demonstrate innate talent; (3) skills focused on a high level of patient centered nutrition care; (4) frequent and ongoing feedback; (5) reading and understanding evidence based practice literature; (6) professional education and networking opportunities; and (7) a non-judgmental learning environment where the student is free to make mistakes. (Abstract word count $=200$ ).

Keywords: Deliberate Practice, Skill Development, Factor Analysis, Pilot Testing, Expertise, and Validation Check

\section{Introduction}

Deliberate practice (DP) serves as a potential conceptual framework to explore activities, attributes, and characteristics leading to expertise in a given field or domain, such as in the education of a Registered Dietitian (RD). First studied by Ericsson, Krampe, and Tesch-Römer (1993), DP encompasses attentive, concentrated, carefully planned activities fundamentally supporting the development of expertise in one's chosen field or domain. The concept of DP was studied across the domains of sports, gaming, music, and allied health professions for the purpose of understanding the key elements of the framework. Practice activities are considered DP under the following conditions: highly structured with purposeful goals; repetitive; feedback with active remediation; and lack of enjoyment with high concentration (Campitelli \& Gobet, 2008; Charness, Tuffiash, Krampe, Reingold, \& Vasyukova, 2005; de Bruin, Kok, Leppink, \& Camp, 2014; de Bruin, Smits, Rikers, \& Schmidt, 2008; Ericsson, 2013; Ericsson \& Charness, 1994; Ericsson \& Lehmann, 1996; Ericsson \& Ward, 2007; Ericsson et al., 1993; Ford, Ward, Hodges, \& Williams, 2009; Haag-Heitman, 2008; Johnson, Tenebaum, \& Edmonds, 2006; Law, Côte, \& Ericsson, 2007; McKinney \& Davis 2003; Moulaert, Verwijnew, Rikers, \& Scherpbier, 2004; Sonnentag \& Kleine, 2000).

In attempts to define DP, researchers have investigated activities such as professional reading, individual and group practice, and individual and group study, which embody DP. Keith and Ericsson (2007) used interviews to highlight those activities, which could be defined as DP, as it related to the ability to typing. The interview questions surveyed participants' skill level, practice activities, and accumulated DP hours. The authors explored the relationship between the contribution of typing abilities, amount of previous experience in typing, DP activities (attending a typing class and individual practice time) and typing performance. In a similar attempt to define DP in nursing, Haag-Heitman (2008) developed an interview tool to identify essential personal and environmental attributes modulating the attainment of expert performance in practicing clinical nurses. Choosing a diverse and dynamic work, lifelong self-directed focus, and positive and engaged demeanor were the three important DP themes within the profession of nursing.

In addition to interviews, questionnaires have been developed to successfully explore the relationship between DP activities and expert achievement in the fields of teacher education, nursing, and medical school education (Dunn \& Shriner, 1999; Haag-Heitman, 2008; 
Moulaert et al., 2004). Similar DP themes between the two professions emerged when comparing the fields of teaching and nursing. Dunn \& Shriner (1999) and Haag-Heitman (2008) highlighted the need for continued professional development, lifelong learning, and ensuring self-reflection to improve one's overall performance. The DP activities in medical school education focused on academic aspects of training future physicians and highlighted the importance of including questions on self-directed studying techniques, type and amount of reading professional literature, and type and number of books owned (Moulaert, Verwijnew, Rikers, \& Scherpbier, 2004).

In previous research, semi-structured interviews were employed to identify a list of activities that encompass DP within an allied health education program, specifically within a dietetics education program. Over 100 activities, attributes, and characteristics of DP emerged. The identified elements were classified into categories, using a closed card sort method, reflective of the constructs defined in DP research. Preceptors were recruited from a convenience sample of Dietetic Internship Directors to complete the closed card sorting activity. A total of 45 preceptors fully completed the closed card sort utilizing an online electronic platform-OptimalSort $\odot$. The mean age of the participants was 42.9 years ( $\mathrm{SD} \pm 12.6)$. The mean years in the profession were 17.6 years $(\mathrm{SD} \pm 12.2)$ and 11.2 years serving as a preceptor $(\mathrm{SD} \pm 8.8)$. The average time to complete the card sorting activity was 41:09 minutes ( $\mathrm{SD} \pm 34: 33$ ). The participants were not financially or otherwise compensated. Based on the results of a closed card sort, those items with acceptable levels of agreement were included in the development of an instrument to define DP in supervised dietetics education (Haubrick, Molaison, Huye, Landry, \& Mohn, 2018). Determining important activities, attributes, and characteristics leading to expert is of value to the body of knowledge of deliberate practice and fills a gap, which exists between deliberate practice and the professional domain arena. The purpose of this manuscript is to evaluate reliability and validity of an instrument defining DP in dietetics supervised practice based on the opinions of practitioners and educators in dietetics and allied-health professions.

\section{Methods}

Card sorting, which categorizes like information, was utilized in previous research to group like activities, attributes, and characteristics into the core constructs reflective of DP. After the completion of the card sorting activity, cards with acceptable levels of percent agreement (e.g., 43\% and higher) and theoretical support were used to develop items for a draft instrument (Huye, 2011; Spencer, 2009). The items used represented DP activities, attributes, and characteristics (Haubrick et al., 2018). A total of 55 items, plus four randomly inserted validation (bogus) check items, were included in the draft instrument for use in the preliminary item tryout phase (Huang, Curran, Keeny, Poposki, \& DeShon, 2012; Meade \& Craig, 2012). The instrument included basic demographic data (i.e., sex, years in dietetics practice, age, highest degree obtained, role in the dietetics profession, and state of residence).

A 7-point Likert-type scale was used to determine the level of agreement with the listed activities in order to define DP in dietetics education (Dunn \& Shriner, 1999; Likert, 1932; Moulaert et al., 2004). The draft instrument underwent face and content validity testing to assure understanding of the instrument by the participants and to eliminate irrelevant items 
(Lynn, 1986; Thomas, Hathaway, \& Arheart, 1992). Other items reviewed during the face validity testing included grammar, typical completion time, usefulness of the scale in assessing agreement, and clarity of statements (Burns \& Grove, 2009; Johnson \& Christensen, 2012; Walonick, 2010). Participants were allowed to provide suggestions to include any items they felt were missing. To encourage participation, a drawing for one $\$ 50$ gift card was offered to those who completed the review.

The draft instrument was revised based on the feedback provided during the face validity testing. The instrument was initially evaluated to ensure reliability using Cronbach's $\alpha$. An internal consistency goal of 0.70 or higher was desired to help identify items that did not fit within the proposed categories of DP activities (Burns \& Grove, 2009).

After revisions, 1,100 members of the Academy of Nutrition and Dietetics' (Academy) Practice Group - Nutrition and Dietetics Educators and Preceptors (NDEP)—were invited, via an email listserv request, to participate. A hyperlink to the instrument was included within the email request. In addition to the initial email request, a two-week reminder email was also sent to NDEP members via the listserv. The membership of NDEP is open to any Academy member, who pays the dues for an additional practice group. Membership of NDEP includes dietetics educators and preceptors who work with students during practicum with a general understanding of the learning activities partaken during supervised practice, and general practitioners who wish to join the NDEP practice group. Additionally, NDEP members were encouraged to send the questionnaire out to other educators and preceptors who may not be a member of NDEP to increase the number of potential participants. To encourage participation, a drawing for one $\$ 100$ gift card and a drawing for two $\$ 50$ gift cards were offered to those who completed the review. To assure at least fair estimated factor reliability, a sample size of 200-300 was the goal for this portion of the research (Field, 2009; Mertler \& Vannatta, 2013).

An exploratory factor analysis (EFA) was used to determine construct validity of the revised instrument (Burns \& Grove, 2009; Johnson \& Christensen, 2012). Principal axis factoring was chosen over principal component analysis because of the primary goal of identification of constructs (Field, 2009). During this step, scree plots for the number of potential factors, amount of variance explained by each factor, and the loading for each item on the factor were evaluated. The minimal acceptable cut off point for factor loading in an unknown model is 0.30 (Burns \& Grove, 2009; Mertler \& Vannatta, 2013). Stevens (2002) recommended for a sample size of 200 a loading of at least 0.364 to be considered significant and a sample size of 300 a loading of at least 0.298 to be considered significant. Therefore, a conservative cut off point for factor loading was established at 0.35 .

The goal of the factoring was to achieve simple structure with items loading only on one construct; therefore, simple structure was chosen over parallel analysis and Velicer's minimum average partial (MAP) to avoid over- or under-loading of items into a construct (O'Connor, 2000). Since it was anticipated the constructs would correlate based on their theoretical overlap, an oblique factor (direct oblimin) rotation was utilized. (Burns \& Grove, 2009; Field, 2009; Mertler \& Vannatta, 2013) Cross correlations between the extracted factors as well as Cronbach alphas were calculated after the factor solution. SPSS $®$ (version 23) was used to analyze the data. 


\section{Institutional Review Board}

This project was reviewed and approved by the Institutional Review Board (IRB) at the University of Southern Mississippi with an expedited review and implied consent was obtained from all participants.

\section{Results}

A total of 23 individuals participated in the preliminary item tryout. Of the participants, 22 were female and all held the Registered Dietitian (RD) credential. The majority of the respondents $(n=16)$ were practitioners, with two respondents employed as program directors of an accredited dietetics education program (one from a dietetic internship and one from a didactic program in dietetics) and four faculty members. The mean age of the respondents was 39.6 years $(S D \pm 14.3)$ with 14.1 years of experience $(S D \pm 13.2)$.

Of those respondents who completed the evaluation of the instrument for face and content validity, $100 \%(n=21)$ reported the instructions for the instrument were clear, items were written clearly, the overall layout and flow was clear and easy to understand, and the length of the instrument was appropriate. The majority of respondents preferred to use the term "intern" ( $n=13)$ compared to "student" $(n=8)$; therefore, the term "intern" was used in the final instrument. Respondents were asked if there were any items they would exclude from the instrument and 3 out of 21 respondents stated "yes" to this question. However, only one respondent provided an actionable comment indicating some statements only elicited positive responses. After reviewing the frequency report for responses, six scale items were identified with $100 \%$ responses of either agreed or strongly agreed responses. These items were rewritten to make the statements elicit responses across the scale spectrum compared to eliciting only highly positive responses. For example, "A learning environment is safe, challenging, and positive" was rewritten to "A learning environment that supports the intern."

Cronbach alphas were calculated to determine construct consistency for items of the proposed instrument (Table 1). All values were above the threshold of .70 except for "Methods of coaching or precepting," which was .302 . When considering the strong theoretical backing for this construct, researchers elected to retain in the scale. Thus, the 55 initial items were included in the final instrument.

Table 1. Reliability of constructs from preliminary item tryout

\begin{tabular}{lll}
\hline Construct & Number of items in construct & Cronbach alpha \\
\hline Student possesses natural abilities to be successful in the profession & 14 & .866 \\
Methods of coaching or precepting & 4 & .302 \\
Supervised practice activities that need more time & 6 & .807 \\
Methods to increase performance & 7 & .845 \\
Characteristics of student-preceptor relationship & 13 & .779 \\
Activities that promote lifelong learning & 4 & .873 \\
Foundational education activities to be a successful practitioner & 6 & .746 \\
Total & $55^{\mathrm{a}}$ & .926 \\
\hline
\end{tabular}

Although the current membership by the NDEP was reported to be 1,100 members, a total 
1,316 NDEP members received the initial email request. Of 1,316 potential participants, 430 individuals opened the initial email request $(32.7 \%)$. Two weeks later, a reminder email was sent out to all members of NDEP. At this point, 1,318 members received the reminder email request and 489 members opened the email (37.1\%). The initial email request and two-week reminder email were sent to the same pool of participants; therefore, no method was available to know how many members of NDEP opened both messages. Additionally, researchers requested NDEP members pass the email along to other professionals in their network who may be interested in responding. Utilizing this snowball sampling technique may have added to the total number of potential participants, which cannot be quantified.

A total of 323 individuals launched the instrument link. Of those, 255 (79.0\%) respondents completed the instrument with an additional 68 (21.0\%) partially completed responses, which were excluded from final analyses. Data from participants who did not complete or accurately complete $75 \%$ (three out of four) of the validation check questions were also eliminated from the data set $(n=11 / 4.3 \%)$. A total of 244 useable responses were available for data analysis. Prior to data analysis, missing data points were replaced with the linear trend point of each item of the scale (Field, 2009).

The participants who completed the instrument held the RD credential $(99.2 \%)$, were predominately female (97.5\%), were between the ages of 51-60 (27.0\%), and had 31-40 years of experience $(26.2 \%)$. More than half of the participants had earned a masters $(60.2 \%)$ and nearly a third held a doctorate (27.9\%) degree. See Table 2 for a complete demographic profile of the participants.

Initial visual evaluation of the scree plot indicated extraction of five to nine factors. The most widely utilized tool for factor extraction is The Kaiser's Criterion, which recommends extraction of all factors with eigenvalues greater than one. Unfortunately, Kaiser's Criterion tends to over-estimate the number of factors to extract; therefore, parallel analysis and Velicer's minimum average partial (MAP) were calculated (Field, 2009). Parallel analysis, which tends to over identify, indicated to retain an eight-factor solution. Velicer's MAP, which tends to under identify, indicated to retain a six-factor solution (Field, 2009; O'Connor, 2000). Because of the potential over and under estimations of parallel analysis and Velicer's MAP, the need for factors to make theoretical sense, and the goal of simple structure, extraction of seven factors were retained in the final analysis with a factor loading cut off of 0.35 .

The Kaiser Meyer Olkin (KMO) measure verified the sampling adequacy of the analysis. The KMO measure was equal to .827, which is considered "good" (Field, 2009). Barlett's test of sphericity chi-square $(496)=3084.178, p<.001$, which indicated correlations between items were sufficiently large for principal axis factoring. Table 3 details the factors of the seven-factor simple structure model, which explained $59.72 \%$ of the variance. 
Table 2. Demographic profile of participants $(\mathrm{N}=244)$

\begin{tabular}{|c|c|c|}
\hline Characteristics & $n$ & Percent \\
\hline \multicolumn{3}{|l|}{ Gender $^{\mathrm{a}}$} \\
\hline Male & 6 & 2.5 \\
\hline Female & 236 & 97.5 \\
\hline \multicolumn{3}{|l|}{ Credentials $^{\mathrm{b}}$} \\
\hline $\mathrm{RD}$ or RDN & 242 & 99.2 \\
\hline DTR or NDTR & 2 & 0.8 \\
\hline Other & 19 & 7.8 \\
\hline \multicolumn{3}{|l|}{ Years in practice } \\
\hline $0-10$ & 62 & 25.4 \\
\hline $11-20$ & 57 & 23.4 \\
\hline $21-30$ & 55 & 22.5 \\
\hline $31-40$ & 64 & 26.2 \\
\hline$>40$ & 6 & 2.5 \\
\hline \multicolumn{3}{|l|}{$\mathrm{Age}^{\mathrm{a}}$} \\
\hline $21-30$ & 18 & 7.7 \\
\hline $31-40$ & 61 & 26.1 \\
\hline $41-50$ & 51 & 21.8 \\
\hline $51-60$ & 63 & 27.0 \\
\hline $61-70$ & 38 & 16.2 \\
\hline$>70$ & 3 & 1.3 \\
\hline \multicolumn{3}{|l|}{ Role in dietetics ${ }^{\mathrm{a}}$} \\
\hline Program Director $^{\mathrm{a}}$ & 100 & 41.2 \\
\hline DPD (Didactic Program in Dietetics) & 26 & 26.0 \\
\hline DI (Dietetic Internship Program) & 61 & 61.0 \\
\hline CP (Coordinated Program) & 10 & 10.0 \\
\hline DT (Dietetic Technician Program) & 2 & 2.0 \\
\hline Faculty member & 68 & 30.0 \\
\hline DPD & 31 & 45.6 \\
\hline DI & 16 & 23.5 \\
\hline $\mathrm{CP}$ & 14 & 20.6 \\
\hline DT & 6 & 8.8 \\
\hline Other & 1 & 0.2 \\
\hline Practitioner & 49 & 20.1 \\
\hline Practitioners (current preceptors) & 43 & 87.8 \\
\hline Practitioners (not current preceptors) & 6 & 12.2 \\
\hline Other & 26 & 10.7 \\
\hline \multicolumn{3}{|l|}{ Highest degree obtained } \\
\hline 2 year degree & 0 & 0.0 \\
\hline 4 year degree & 29 & 11.9 \\
\hline Masters & 147 & 60.2 \\
\hline Doctorate & 68 & 27.9 \\
\hline \multicolumn{3}{|l|}{ NDEP Region } \\
\hline 1 & 45 & 18.4 \\
\hline 2 & 30 & 12.3 \\
\hline 3 & 27 & 11.1 \\
\hline 4 & 50 & 20.5 \\
\hline 5 & 33 & 13.5 \\
\hline 6 & 28 & 11.5 \\
\hline 7 & 31 & 12.7 \\
\hline
\end{tabular}

${ }^{\mathrm{a} C}$ Category is missing data point(s)

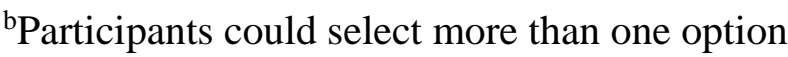


Table 3. Factor loadings for a seven-factor structure including eigenvalues and percentage shared variance

\begin{tabular}{|c|c|c|c|}
\hline Factors & Loading & $\lambda$ & $\%$ Shared variance \\
\hline Factor one: Methods to increase performance & & 6.99 & 21.83 \\
\hline Q33. A dedicated study schedule & .754 & & \\
\hline Q27. Intern reviews notes from coursework & .665 & & \\
\hline Q25. A quiet and conducive environment for studying & .612 & & \\
\hline Q13. Studying with flash cards & .589 & & \\
\hline Q47. Outlines to assist the intern when studying & .573 & & \\
\hline Q18. Intern-developed case scenarios used as a study guide & .437 & & \\
\hline Q03. Individual and group practice exams & .430 & & \\
\hline Factor two: Natural abilities & & 3.11 & 9.71 \\
\hline Q09. Emotional intelligence to cultivate positive relationships & -.850 & & \\
\hline Q14. Positive relationships where the intern is able to connect with others & -.609 & & \\
\hline Q12. Personal interactions allowing the intern to demonstrate mature character & -.510 & & \\
\hline Q19. Culturally competent communication techniques are used by the intern & -.509 & & \\
\hline Q07. Resiliency in a difficult situation & -.397 & & \\
\hline Factor three: Activities requiring focused time & & 2.67 & 8.34 \\
\hline Q17. More time spent on critical care activities as compared to all other activities & .916 & & \\
\hline $\begin{array}{l}\text { Q23. More time spent on advanced clinical nutrition activities as compared to all other } \\
\text { activities }\end{array}$ & .856 & & \\
\hline Q02. More time spent on nutrition support activities as compared to all other experiences & .704 & & \\
\hline Q45. More time spent on nutrition assessment skills as compared to all other experiences & .570 & & \\
\hline Factor four: The coaching process & & 2.07 & 6.47 \\
\hline Q49. Designated time for the preceptor to provide feedback & .625 & & \\
\hline Q46. Preceptors provide feedback in a one on one setting & .574 & & \\
\hline Q42. Formal, end of rotation evaluations & .512 & & \\
\hline Q43. A common set of goals established between the intern and the preceptor & .502 & & \\
\hline $\begin{array}{l}\text { Q50. Additional feedback is provided when a intern who does not possess natural and } \\
\text { academic abilities }\end{array}$ & .488 & & \\
\hline Q59. Preceptors provide ongoing and daily feedback & .437 & & \\
\hline Factor five: Educational activities within the curriculum & & 1.84 & 5.75 \\
\hline $\begin{array}{l}\text { Q41. Develop an understanding of research and statistical methodology by reading journal } \\
\text { articles }\end{array}$ & .809 & & \\
\hline Q40. Exposure to specialty information by reading journal articles & .704 & & \\
\hline Q58. Required readings to stay abreast of current topics & .555 & & \\
\hline Q56. A literature review used as part of evidence based practice & .527 & & \\
\hline Factor six: Lifelong learning & & 1.30 & 4.05 \\
\hline $\begin{array}{l}\text { Q39. Professional meetings and conferences to further develop knowledge within one's } \\
\text { practice area }\end{array}$ & .734 & & \\
\hline Q24. Professional network opportunities to further develop knowledge & .679 & & \\
\hline $\begin{array}{l}\text { Q53. Professional organization membership to further develop knowledge within one's } \\
\text { practice }\end{array}$ & .678 & & \\
\hline Factor seven: The learning environment & & 1.14 & 3.57 \\
\hline Q31. Opportunities to practice and develop skills are ample & -.741 & & \\
\hline Q32. A learning environment that supports the intern & -.722 & & \\
\hline Q22. Preceptors who provide constructive feedback and suggestions for improvement & -.492 & & \\
\hline
\end{tabular}

Note: $\lambda=$ eigenvalues

Table 4 highlights the means and standard deviations for the seven subscales, correlations between the factors, and internal consistency estimates. All factors within the solution noted significant low to moderate correlations (ranging from .169 to .475) except for the relationships between activities requiring focused time and natural abilities $(r=.089)$, lifelong learning $(r=.097)$, and the learning environment $(r=.113)$. All factors within the solution 
demonstrated an acceptable level of internal consistency. Mean differences between factor subscales did not exist between the different groups-educators, practitioners, and preceptors — who participated in the research study.

Table 4. Factor correlations and reliability estimates

\begin{tabular}{|c|c|c|c|c|c|c|c|c|c|}
\hline Factor & $\mathbf{M}^{\mathbf{a}}$ & SD & 1 & 2 & 3 & 4 & 5 & 6 & 7 \\
\hline 1. Methods to increase performance $(n=7)$ & 4.49 & .90 & $(.82)$ & & & & & & \\
\hline 2. Natural abilities $(n=5)$ & 6.13 & .62 & $.279^{\mathrm{b}}$ & $(.80)$ & & & & & \\
\hline 3. Activities requiring focused time $(n=4)$ & 4.35 & 1.12 & $.301^{\mathrm{b}}$ & .089 & $(.85)$ & & & & \\
\hline 4. The coaching process $(n=6)$ & 6.14 & .57 & $.407^{\mathrm{b}}$ & $.259^{\mathrm{b}}$ & $.141^{\mathrm{c}}$ & $(.73)$ & & & \\
\hline $\begin{array}{l}\text { 5. Educational activities within the } \\
\text { curriculum }(n=4)\end{array}$ & 5.64 & .79 & $.364^{\mathrm{b}}$ & $.235^{\mathrm{b}}$ & $.171^{\mathrm{c}}$ & $.368^{\mathrm{b}}$ & $(.80)$ & & \\
\hline 6. Lifelong learning $(n=3)$ & 5.46 & .89 & $.384^{\mathrm{b}}$ & $.409^{\mathrm{b}}$ & .097 & $.240^{\mathrm{b}}$ & $.383^{\mathrm{b}}$ & (.73) & \\
\hline 7. The learning environment $(n=3)$ & 6.52 & .59 & $.169^{\mathrm{b}}$ & $.475^{\mathrm{b}}$ & .113 & $.328^{\mathrm{b}}$ & $.143^{\mathrm{b}}$ & $.172^{\mathrm{b}}$ & $(.73)$ \\
\hline Total instrument $(n=32)$ & 5.46 & .49 & & & & & & & $(.88)$ \\
\hline
\end{tabular}

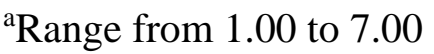

${ }^{\mathrm{b}}$ Correlation is significant at the 0.01 (2-tailed)

${ }^{\mathrm{c}}$ Correlation is significant at the 0.05 (2-tailed)

Note: Cronbach's alpha levels appear in the parentheses on the diagonal

\section{Discussion}

The factor analysis yielded a seven-factor solution, which provided an initial definition of deliberate practice within supervised dietetics education in order to apply a working definition of deliberate practice to supervised dietetics education. Many of the factors identified - such as methods to increase performance, need for feedback and remediation, and natural abilities - within the factor solution correspond directly to previous results within the literature.

'Methods to increase performance' was the strongest factor, one of two factors with the most factor loadings, and explained the greatest amount of shared variance. All of the items within this particular factor related to studying, study techniques, and the studying environment. Study techniques are an important aspect to improve performance within DP (Charness et al., 2005; de Bruin et al., 2008; Keith \& Ericsson, 2007; Moulaert et al., 2004). Moulaert and colleagues (2004) noted in their research, participants spent an average of 31.9 hours per week on study-related activities with lower achieving students spending less time on self-directed study activities $(2.3$ hours, $p<0.05)$. Studying, self-study, study techniques are important when defining DP in supervised dietetics education as indicated by a Cronbach's alpha of .82 and as in the previous DP literature (Charness et al., 2005; de Bruin et al., 2008; Keith \& Ericsson, 2007; Moulaert et al., 2004).

One must have innate talent-genetic factors of exceptional performance which are not necessarily obtained by education or training, plus the dedication of practice that is deliberate in nature, in order to achieve expert performance (Ericsson et al. 1993; Galton, 1979; Gangé, 
1999). Emotional intelligence, positive relationships, mature personal interactions, culturally competent communication, and resiliency were important natural abilities attributes and characteristics in supervised dietetics education. The item Personal interactions allowing the intern to demonstrate a mature character was originally written for a differing construct during the preliminary item tryout; however, the item theoretically made sense within the 'Natural abilities' construct after the EFA, since having a mature character could be considered a natural attribute of an intern (Gangé, 1999). The inclusion of natural abilities in the equation of obtaining expert performance is highlighted within previous literature; similarly, the results of this research support the inclusion of natural abilities $(\alpha=.80)$ as a part of the definition of DP in supervised dietetics education (Ericsson et al. 1993; Galton, 1979; Hodges, Kerr, Starkes, Weir \& Nananidou, 2004).

The concept of time is important because the framework of DP indicates achieving expert performance will occur only after a sufficient amount of practice time (de Bruin et al. 2008; Law et al., 2007; Ward, Hodges, Starkes \& Williams, 2007). The items within the factor of 'Activities requiring focused time' provide support for the need to focus more time on critical care, clinical nutrition, nutrition support, and nutritional assessment activities when defining DP in supervised dietetics education $(\alpha=.85)$. Activities needing more focused time herein include critical care, clinical nutrition, nutrition support, and nutritional assessment, which converge to craft the more medically complex clinical nutrition activities of a RD. The support for medically complex clinical nutrition activities is in alignment with the 2017 RD national credentialing examination blueprint. The RD exam focuses $40 \%$ of the overall test questions on nutritional care for individuals and groups (Commission on Dietetic Registration, 2016).

Providing active remediation and feedback are important characteristics when defining DP (de Bruin et al., 2008; Dunn \& Shriner, 1999; Ericsson, 2013; Ericsson \& Charness, 1994; Ericsson \& Lehmann, 1996; Ericsson \& Ward, 2007; Ericsson et al., 1993; Ford et al., 2009; Johnson et al., 2006; Law et al., 2007; Moulaert et al., 2004;). The outcome of the EFA collapsed the items 'Methods of coaching and precepting' and 'Characteristics of the intern-preceptor relationship' into one factor named 'The coaching process.' The factor had the second most number of factor items loaded $(n=6)$ as well as $6.5 \%$ shared variance of the overall solution. Therefore, 'The coaching process,' providing active remediation and feedback, is important when defining DP in supervised dietetics education and within the DP literature albeit a lower alpha coefficient in this construct.

Important to any curriculum are the educational activities, which guide the learning process. Thus, determining practice activities within the educational curriculum to improve performance are a necessary function, and the need is evident through the literature. ${ }^{2,39}$ Interestingly, the items within the factor 'Educational activities with the curriculum' focused completely on reading information to support foundation knowledge and reading research literature. These particular educational activities are essential when defining DP within supervised dietetics education $(\alpha=.80)$ as they provide the foundation to the learning process. The idea that professional reading is a key activity in DP was supported in areas such as chess, teaching, medical school education, and rhythmic gymnastics (Campitelli \& Gobet, 2008; 
Charness et al., 2005; Moulaert et al., 2004; Dunn \& Shriner, 1999; Ward et al., 2007).

Dunn and Shriner (1999) and Haag-Heitman (2008) noted the importance of the lifelong learning process, in particular attendance at seminars and workshops within their literature. Attendance at professional meetings, networking opportunities, and membership within a professional organization were the items that loaded to the factor of 'Lifelong learning.' The convergence of the items within this factor provided theoretical support $(\alpha=.77)$ for the need of an individual's continued learning and self-reflection throughout his or her dietetics' career and is supported within the literature.

Lastly, the factor identified as 'The learning environment' was not found in previous literature and is a newly proposed construct reflective of DP. Unfortunately, this factor only had three items loaded, loaded last in the EFA, and the smallest percentage shared variance as well as an alpha coefficient close to the threshold of $\geq .70$. Therefore, future testing could include the addition of new items to strengthen this factor.

In summary, the instrument described within this manuscript is a novel instrument measuring the activities, attributes, and characteristics of DP in supervised dietetics education based on the opinions of practitioners and educators in dietetics and allied-health professions. The activities, attributes, and characteristics of DP in supervised dietetics education offered many similar, but minor differences in the results compared to the literature. The newly developed instrument included fundamental characteristics of DP such as methods to increase performance, the need for natural abilities, and the importance of feedback and remediation similar to the findings of others defining DP within their chosen field or domain. Also results indicated the inclusion of educational activities within the curriculum and lifelong learning within the instrument, which were a part of the DP literature reflective of the professional domain (Dunn \& Shriner, 1999; Haag-Heitman, 2008). Noted differences of the results indicate the inclusion of elements of the learning environment as well activities requiring focused time. This is the first instrument, to the knowledge of this researcher, measuring DP in supervised dietetics education.

\subsection{Limitations}

There were several limitations to the research. First, the sample size for the EFA $(n=244$ participants) was considered "fair" to "good" for estimated factor reliability (Walonick, 2010). To provide improved results for an EFA, a sample size of $\geq 300$ would be ideal to strengthen the results. Since not all educators and preceptors are NDEP members, it would be beneficial to determine alternative methods to reach a larger pool of educators and preceptors to increase the sample size to larger than 300 participants. Potentially, administering the questionnaire to all members of the Academy of Nutrition and Dietetics, then filter by categories of educator and preceptor could be an alternative approach to reach educators and preceptors who are a member of the Academy but not a member of NDEP. Lastly, DP has never being defined in supervised dietetic practice and thus there are limited data, within the literature, on defining activities that are required in the development of an allied health professional. The lack of data creates a gap within the literature on the topic of DP in supervised dietetics education. 
6. Implications for Research and Practice

Future research may first include the development of new items, especially for the constructs, 'lifelong learning' and 'the learning environment', to strengthen the overall reliability of the instrument. The least number of items loaded on these constructs and these were loaded last in the EFA. In addition, 'lifelong learning' was a new construct not yet mentioned in deliberate practice literature. The lower reliability estimates, while although acceptable in introductory research on instrument development, may need to be improved as psychometric evaluations are conducted on the instrument.

Future utility for this instrument includes the use of predictive statistics to model outcomes in dietetics education. Each mean construct response plus the overall score of the instrument, could be employed to predict such outcomes as employment rates, completion or graduation rates of interns, placement into graduate school, and/or RD examination scores. Historically, dietetic internship directors use academic markers (i.e. grade point average or Graduate Record Exam scores) to predict success on passage of the RD credentialing examination and thus initiate potential admittance into the dietetics program. Current research predicting RD credentialing examination success is helpful to inform dietetic internship directors when to admit the most qualified student, yet, these studies do not aim to address what types of educational activities make one successful or competent to practice in dietetics. Thus, by defining DP in supervised dietetics education, important qualitative activities, attributes, and characteristics, which are missing from the research focusing on specific academic markers for success, are able to be quantified. Merging the qualitative elements of expert performance of this research with the quantitative academic measures could provide further benefit to those involved in the education and training of a Registered Dietitian.

\section{Conclusion}

The purpose of this manuscript was to establish reliability and validity of an instrument measuring DP in dietetics supervised practice, based on the opinions of practitioners and educators in dietetics and allied-health education, so characteristics of DP in dietetics education can be defined. Although DP in dietetics has not been defined in the literature, the findings of this research indicated a seven-factor solution with adequate factor loadings above $+/-.35$ and sufficient alpha coefficients. From the outcome of this research, DP within supervised dietetics education can be defined by the following characteristics: (1) regular and systematic opportunities to practice skills and hone knowledge; (2) opportunities embedded within experiential practice to demonstrate innate talent; (3) dedicated time to cultivate skills focused on a high level of patient centered nutrition care; (4) frequent and ongoing feedback; (5) activities devoted to reading and understanding evidence based practice literature; (6) professional education and networking opportunities; and (7) a non-judgmental learning environment where the student is free to make mistakes. The definition of DP in supervised dietetics education encompasses many of the important facets outlined from the literature. Due to the limitations outlined in this study, further instrument testing may be needed to confirm the proposed definition of DP in supervised dietetics education. 
Acknowledgement

We thank Dr. Ulric Chung for comments that greatly improved the manuscript and scope of this project.

\section{References}

Burns, N., \& Grove, S. (2009). The practice of nursing research: Appraisal, synthesis, and general evidence. St. Louis, Missouri: Saunders.

Campitelli, G., \& Gobet, F. (2008). The role of practice in chess: A longitudinal study. Learning and Individual Differences, 18, 446-458. Retrieved from http://10.1016.j.lindif.2007.11.006

Charness, N., Tuffiash, M., Krampe, R., Reingold, E., \& Vasyukova, E. (2005). The role of deliberate practice in chess expertise. Applied Cognitive Psychology, 19, 151-165. Retrieved from http://10.1002/acp.1106

Commission on Dietetic Registration. (2016). Registered Dietitian Examination-test specifications. Retrieved from https://www.cdrnet.org/vault/2459/web/files/RDTestSpecs 2017.pdf

de Bruin, A., Kok, E., Leppink, J., \& Camp, G. (2014). Practice, intelligence, and enjoyment in novice chess players: A prospective study at the earliest stage of chess career. Intelligence, 45, 18-25. Retrieved from http://10.1016/j.intell.2013.07.004

de Bruin, A., Smits, N., Rikers, R., \& Schmidt, H. (2008). Deliberate practice predicts performance over time in adolescent chess players and drop-outs: A linear mixed model analysis. British Journal of Psychology, 99, 473-497. Retrieved from http://10.1348/000712608X295631

Dunn, T., \& Shriner, C. (1999). Deliberate practice in teaching: What teachers do for self-improvement. Teaching and Teacher Education, 15, 631-651.

Ericsson, K. (2013). Training history, deliberate practice and elite sports performance: An analysis in response to Tucker and Collins review-what makes champions? British Journal of Sports Medicine, 47, 533-535. Retrieved from http://10.1136/bjsports-2012-091767

Ericsson, K., \& Charness, N. (1994). Expert performance: Its structure and acquisition. American Psychologist, 49, 725-747.

Ericsson, K., \& Lehmann, A. (1996). Expert and exceptional performance: Evidence of maximal adaptation to task constraints. Annual Review of Psychology, 47, 283-305.

Ericsson, K., \& Ward, P. (2007). Capturing the naturally occurring superior performance of experts in the laboratory. Current Directions in Psychological Science, 16, 346-350.

Ericsson, K., Krampe, R., \& Tesch-Romer, C. (1993). The role of deliberate practice in the acquisition of expert performance. Psychological Review, 100(3), 363-406. 
Field, A. (2009). Discovering statistics using SPSS. Thousand Oaks, California: Sage Publications, Inc.

Ford, P., Ward, P., Hodges, N., \& Williams, A. (2009). The role of deliberate practice and play in career progression in sport: The early engagement hypothesis. High Ability Studies, 20, 65-75. Retrieved from http://10.1080/13598130902860721

Galton, F. (1979). Hereditary genius: An inquiry into its laws and consequences. London, England: Julian Friedman (Original work published 1869).

Gangé, F. (1999). My convictions about the nature of abilities, gifts, and talents. Journal for the Education of the Gifted, 22, 109-136.

Haag-Heitman, B. (2008). The development of expert performance in nursing. Journal for Nurses in Staff Development, 24(5), 203-211.

Haubrick, K., Molaison, E., Huye, H., Landry, A., \& Mohn, R. (2018). Qualitative methods to define deliberate practice in supervised dietetics education. NDEP-Line, Summer, 5-15. Retrieved from http://cms.devbridge.com/depdpg.org/44deff9e-59b1-4114-baec-767b95e 203ae.pdf

Hodges, N., Kerr, T., Starkes, J., Weir, P., \& Nananidou, A. (2004). Predicting performance times from deliberate practice hours for triathletes and swimmers: What, when, and where is practice important? Journal of Experimental Psychology: Applied, 10, 219-237. Retrieved from http://10.1037/1076-898X.10.4.219

Huang, J., Curran, P., Keeny, J., Poposki, E., \& DeShon, R. (2012). Detecting and deterring insufficient effort responding to surveys. Journal of Business and Psychology, 27, 99-114. Retrieved from http://10.1007/s10869-011-9231-8

Huye, H. (2011). Development of an instrument measuring the perceived attributed of using a healthy diet innovation (Doctoral dissertation). Retrieved from http://aquila.usm.edu/dissertations/504/

Johnson, B., \& Christensen, L. (2012). Educational research: Quantitative, qualitative, and mixed approaches. Thousand Oaks, California: SAGE Publications, Inc.

Johnson, M., Tenenbaum, G., \& Edmonds, W. (2006). Adaptation to physically and emotionally demanding conditions: The role of deliberate practice. High Ability Studies, 17, 117-136. Retrieved from http://10.1080/13598130600947184

Keith, N., \& Ericsson, K. (2007). A deliberate practice account of typing proficiency in everyday typists. Journal of Experimental Psychology: Applied, 23, 135-145. Retrieved from http://10.1037/1076-898X.13.3.135

Law, M., Côte, J., \& Ericsson, K. (2007). Characteristics of expert development in rhythmic gymnastics: A retrospective study. International Journal of Sport and Exercise Psychology, 5, 82-103. Retrieved from http://10.1080/162197X.2008.9671814

Likert, R. (1932). A technique for the measurement of attitudes. Archives of Psychology, 140, 
44-53.

Lynn, M. (1986). Determination and quantification of content validity. Nursing Research, 35, 382-385.

McKinney, E., \& Davis, K. (2003). Effects of deliberate practice on crisis decision performance. Human Factors, 45, 436-444.

Meade, A., \& Craig, S. (2012). Identifying careless responses in survey data. Psychological Methods, 17, 437-455. Retrieved from http://10.1037/a0028085

Mertler, C., \& Vannatta, R. (2013). Advanced and multivariate statistical methods. Glendale, California: Pyrczak Publishing.

Moulaert, V., Verwijnew, M., Rikers, R., \& Scherpbier, A. (2004). The effects of deliberate practice in undergraduate medical education. Medical Education, 38, 1044-1052. Retrieved from http://10.1111/j.1365-2929.2004.01954.x

O'Conner, B. (2000). SPSS and SAS programs for determining the number of components using parallel analysis and Velicer's MAP test. Behavior Research Methods, Instruments, \& Computers, 32, 396-402.

OptimalSort [Computer software]. Wellington and Wairarapa, New Zealand: Optimal Workshop.

Sonnentag, S., \& Kleine, B. (2000). Deliberate practice at work: A study with insurance agents. Journal of Occupational and Organization Psychology, 73, 87-102.

Spencer, D. (2009). Card Sorting. Brooklyn, New York: Rosenfeld Media, LLC.

SPSS Statistical Software (Version 23) [Computer Software]. IBM: New York.

Stevens, J. (2002). Applied multivariate statistics for social sciences. Hillsdale, New Jersey: Erlbaum.

Thomas, S., Hathaway, D., \& Arheart, K. (1992). Face validity. Western Journal of Nursing Research, 14, 109-112.

Walonick, D. (2010). A selection from survival statistics. Bloomington, Minnesota: StatPack, Inc.

Ward, P., Hodges, N., Starkes, J., \& Williams, A. (2007). The road to excellence: Deliberate practice and the development of expertise. High Ability Studies, 18, 119-153. Retrieved from http://10.1080/13598130701709715

\section{Copyright Disclaimer}

Copyright reserved by the author(s).

This article is an open-access article distributed under the terms and conditions of the Creative Commons Attribution license (http://creativecommons.org/licenses/by/3.0/). 